\title{
Two cases of accidental hypothermia in Parkinson's disease with unusual E.E.G. findings
}

\author{
S. S. GUBBAY AND D. D. BARWICK \\ From the Regional Neurological Centre, Newcastle General Hospital, Newcastle upon Tyne
}

Increasing awareness of the clinical entity of accidental hypothermia is apparent from case reports and observations in the medical literature in the last seven years. This paper described two patients, both of whom were sufferers from Parkinson's disease, who developed an episode of accidental hypothermia during which unusual and strikingly similar reversible electro-encephalographic changes were recorded.

\section{CASE REPORTS}

CASE 1 A 73-year-old widow, treated for the past four years with benzhexol and benztropine for Parkinson's 'isease, was admitted to the Newcastle General Hospital

10 February 1964. For two years previously she had bwn signs of progressive dementia; her personal habits and recent memory had deteriorated, and she had difficulty in dressing herself and was becoming aggressive in her manner. A week before admission she had felt generally unwell, retired to bed, and thereafter gradually lost her appetite and complained of feeling very cold. On the morning of admission to hospital, she was found in a stuporose condition by relatives with whom she lived.

When examined on admission she responded only to painful stimuli and was cyanosed. Her extremities were cold and the rectal temperature was $91^{\circ} \mathrm{F}$. $\left(32 \cdot 8^{\circ} \mathrm{C}\right.$.). There was marked generalized muscular rigidity with neck stiffness and retraction. All four limbs were held in flexion and she exhibited a flapping tremor of the hands which could be intensified by sudden passive extension of the fingers as well as a slow tremulousness of all four limbs. Deep tendon reflexes were brisk and both plantar responses were flexor. The pulse rate was 100 per minute and of low volume and blood pressure was 120/80 mm.Hg.

Investigations The electrocardiogram was partially obscured by a muscle tremor artefact. There were no J waves and T waves were flat in standard leads $I$ and II. The haemoglobin was 11.7 g. $/ 100 \mathrm{ml}$., W.B.C. $5,200 /$ c.mm., and E.S.R. $53 \mathrm{~mm}$./hour (Westergren). The serum $\mathrm{Na}$ was $130 \mathrm{mEq} / \mathrm{l}$. and serum $\mathrm{K} 4.4 \mathrm{mEq} / \mathrm{l}$. The serum glutamic oxaloacetic transaminase level was 52 international units/ml., serum glutamic pyruvic transaminase 28 international units/ml., serum amylase 266 Somogyi units, and serum cholesterol $249 \mathrm{mg} . / 100 \mathrm{ml}$. A chest radiograph showed extensive patchy consolidation in the lower lobe of the left lung as well as several recent frac- tures of the right lower ribs and a fracture of the left ninth rib. The cardiac outline was within normal limits. The cerebrospinal fluid was clear, colourless and under normal pressure, containing $5 \mathrm{mg}$. of protein $/ 100 \mathrm{ml}$. and no cells. The Wassermann reaction and Reiter's protein complement-fixation test were negative in the cerebrospinal fluid. A skull radiograph was normal.

Progress The patient was treated by very gradual warming in bed with an electric blanket in a well-heated room and received $100 \mathrm{mg}$. of hydrocortisone intramuscularly daily as well as a course of intramuscular penicillin. Her rectal temperature rose to $97^{\circ} \mathrm{F}$. $\left(36 \cdot 1^{\circ} \mathrm{C}\right.$.) in 12 hours, by which time the spontaneous movements had practically ceased. By the third day her conscious state had improved markedly and there was considerable lessening of muscular rigidity. By the time of her discharge from hospital some five weeks after admission, she had regained her former clinical state and exhibited mask-like facies and mild extrapyramidal rigidity of her limbs with occasional mild Parkinsonian tremor of the upper limbs.

Electroencephalographic findings All E.E.G.s reported here were recorded on 16-channel Offner electroencephalographs with scalp electrodes placed according to the international 10-20 system. Recordings were made with bipolar montages, the time constants being all at $1.0 \mathrm{sec}$. and the paper speed being $3 \mathrm{~cm}$./second.

The first E.E.G. was taken 18 hours after admission (Fig. 1), when the patient was semi-comatose, showing only slight withdrawal reponses to painful stimuli. There was, however, no evidence that the E.E.G. appearances described below were modified by external stimuli. There were frequent diphasic or triphasic discharges of rather sharp contour and of up to $300 \mu \mathrm{V}$. in amplitude. These wave forms were widespread throughout both hemispheres, occurring synchronously in all channels and regularly for long periods, often at a frequency of about one per second. At times there were intervals of three to four seconds between successive discharges. The distribution of the potentials in some respects resembled those of so-called mid-vertical sharp waves. Between the sharp wave outbursts the record was often flat and featureless, but sometimes there was a little rhythmical activity at 7 c.p.s. of up to $30 \mu \mathrm{V}$. either generalized or posterior in situation. The changes were interpreted as indicating a generalized disturbance with a severe disorder of function in central structures. A marked similarity between the appearances in this record and those seen in patients with subacute spongioform 

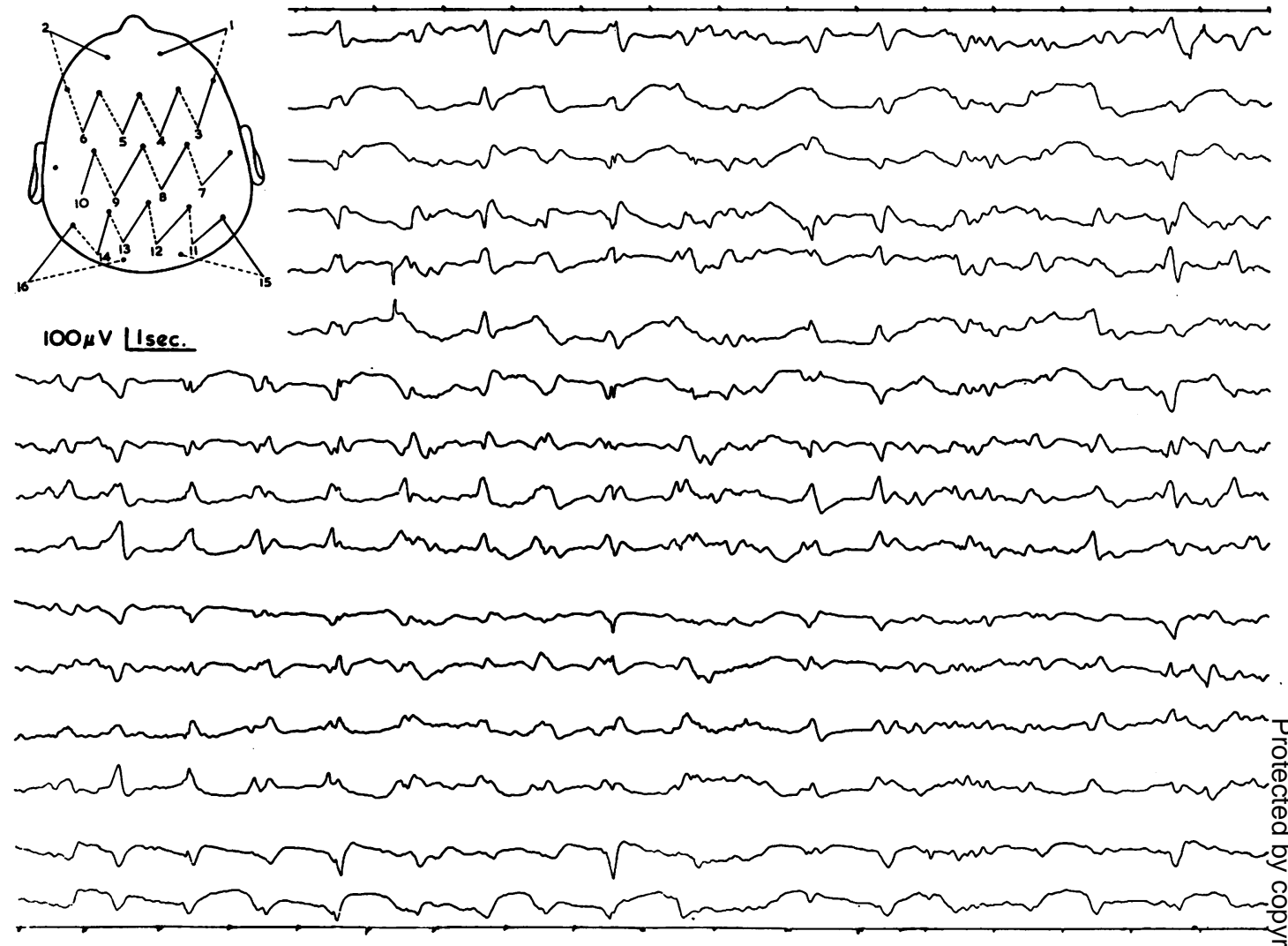

FIG. 1. Initial E.E.G. in first patient shows generalized repetitive and triphasic sharp complexes synchronous in alt channels. These occur at intervals of about one per second.

encephalopathy of the Nevin-Jones type (Jones and Nevin, 1954) was noted.

A second E.E.G. (Fig. 2) obtained after a further 48 hours, when the patient was responsive but confused, was greatly improved. The dominant activity was in the alpha frequency range. There were none of the sharp discharges previously seen, but there were repeated generalized and fairly symmetrical delta waves usually triphasic in outline and synchronous in all channels. These occurred at intervals varying between 3 and 10 seconds, and were unassociated with any external arousing stimuli or readily detectable changes in level of awareness, though they did not appear with the eyes open.

CASE 2 The patient was a 61-year-old spinster who was originally admitted to the Newcastle General Hospital in March 1963. Shortly before admission she had developed stiffness of gait, fixity of facial expression, and mild tremor of both hands. A diagnosis of Parkinson's disease was made and she was given benzhexol. Six days after starting treatment she became drowsy and withdrawn and later confused and hallucinated despite alterations in her drug therapy; because of this deterioration she was admitted to hospital. Her face was expressionless and her voice monotonous. There was a slight slurring dysarthria with increased tone in all four limbs, and cogwheel rigidity and tremor of the upper limbs. The glabellar tap sign was positive and the deep tendon reflexes were brisk with flexor plantar responses. The blood pressure was $170 / 110 \mathrm{~mm}$.Hg. After withdrawal of all drug therapy, her mental state rapidly improved to normal.

Apart from the persistence of the Parkinsonian symptoms, the patient remained well until mid-December 1963 , when with the onset of the very cold weather, she became slow and more unsteady on her feet. Because she appeared to be depressed, she received nortryptilene $25 \mathrm{mg}$. twice daily. Gradually over the next few weeks the patient became slower, more withdrawn and drowsy, and took to her bed. For two days before her re-admission to Newcastle General Hospital on 22 January 1964 she had been lying mute and staring into space unresponsively. When examined at home she was lying in an extremely cold room and her skin felt very cold.

On admission to hospital the patient was conscious, but mute. She was warmer to the touch in the warmly heated $N$ room, and her temperature per axilla was $96 \cdot 6^{\circ} \mathrm{F}$. 

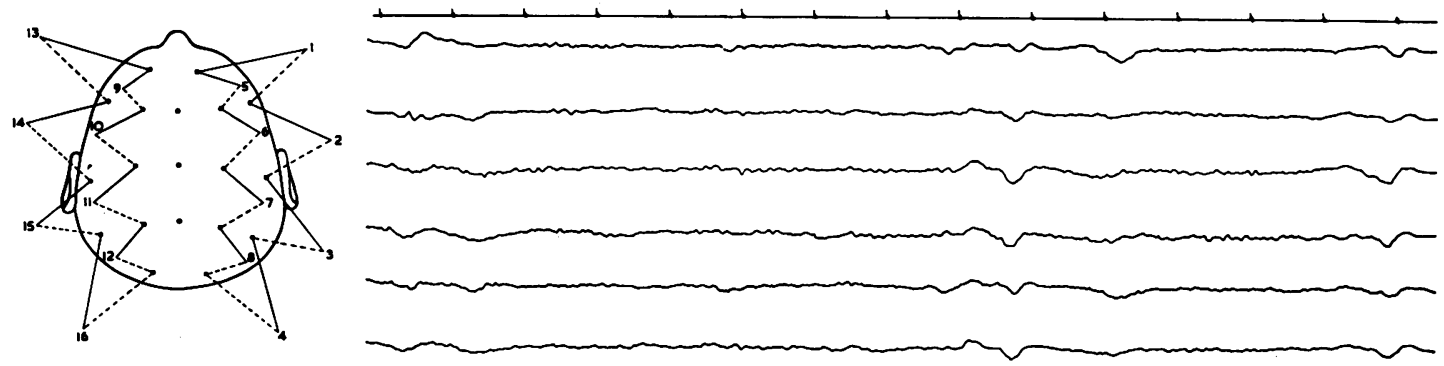

$100 \mu V$ LIsec.
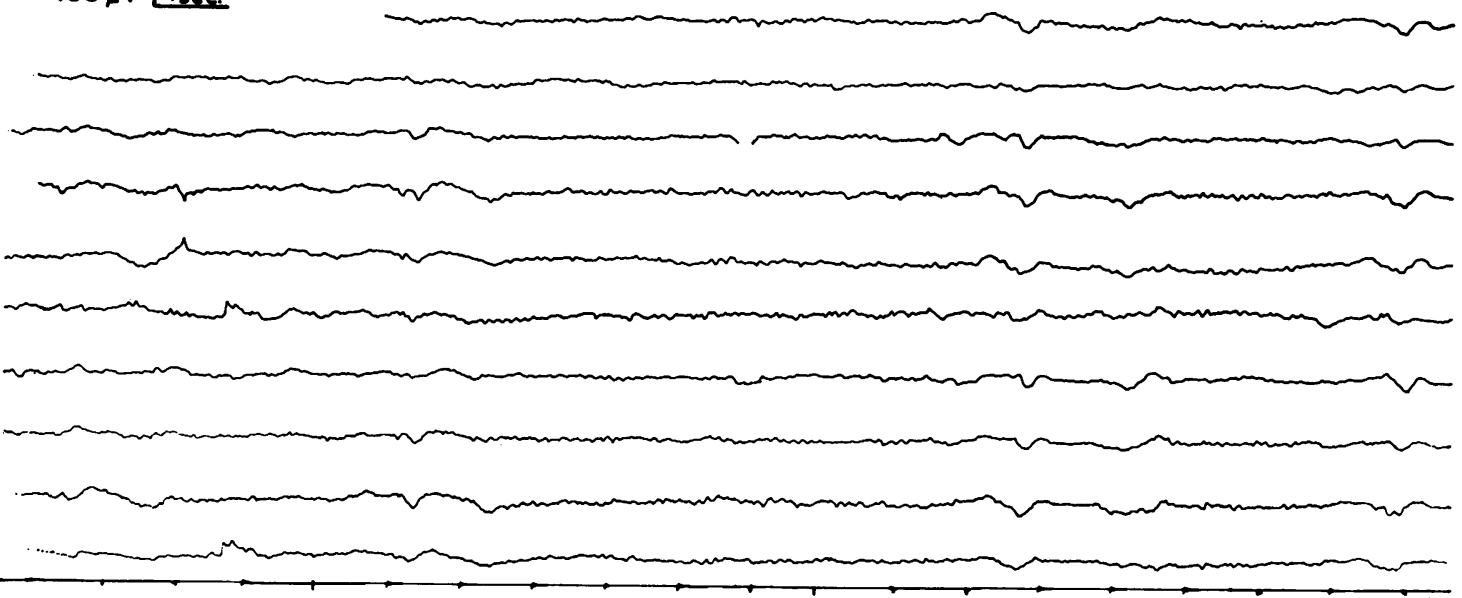

FIG. 2. A second record from the first patient taken a little over 48 hours after the first. Alpha activity now dominates the record but occasional triphasic, generalized slow wave outbursts are seen.

$\left(35.9^{\circ} \mathrm{C}\right.$.). The blood pressure was $120 / 80 \mathrm{~mm} . \mathrm{Hg}$ and pulse rate 70 per minute and regular. There was a peculiar tremulousness of the limbs and face, and a flapping tremor of the hands. These abnormal movements could be accentuated by tapping the muscles or stretching the limbs. The upper limbs were held in flexion and pronation, and the lower limbs in extension, and there was marked rigidity of all four limbs and neck muscles. The deep tendon reflexes were brisk and equal, and both plantar responses were flexor.

The spontaneous movements and hyperirritability of the muscles gradually lessened over the next 48 hours, but otherwise her general clinical state remained much the same for seven days when she regained her speech and showed remarkable improvement, but was slightly confused mentally. Her axillary temperature never fell below the level recorded on admission. Within four weeks she became fully ambulant, and had reverted to a normal state, but still showed the clinical features of Parkinsonism.

Investigations The haemoglobin level was 13.2 g. $/ 100 \mathrm{ml}$., W.B.C. 5,800/c.mm., and E.S.R. $23 \mathrm{~mm}$./hour. A chest radiograph showed clear lung fields and slight cardiomegaly, and a skull radiograph was normal. The serum calcium was $10.4 \mathrm{mg} . / 100 \mathrm{ml}$., phosphate $3.0 \mathrm{mg} . / 100 \mathrm{ml}$., $\mathrm{Na} 143 \mathrm{mEq} . / 1 .$, K $5.9 \mathrm{mEq} . / 1$., and
Cl $95 \mathrm{mEq} . / 1$. The cerebrospinal fluid was clear and colourless and under normal pressure, with a protein content of $73 \mathrm{mg} . / 100 \mathrm{ml}$., and no pleocytosis. The Wassermann reaction and Reiter's complement-fixation test were negative in blood and cerebrospinal fluid. The only electrocardiographic abnormality was that of left ventricular hypertrophy.

Electroencephalographic findings The changes present in the E.E.G. (Fig. 3), obtained on the day of admission, were similar to those found in the first case. There were frequent diphasic and triphasic sharp discharges of peak amplitude up to $400 \mu \mathrm{V}$., occurring synchronously in all areas. These potential changes regularly repeated at a frequency of one per second for much of the record. At other times the interval between successive discharges was 1.5 seconds. Between the discharges the tracing was often flat, though at times some irregular theta and delta activity was seen, mainly in the posterior region. Although the patient was not comatose at the time of the recording, she was mute. The appearances of the E.E.G. did not appear to be correlated with any obvious change in level of awareness although this was difficult to assess at the time. Arousing stimuli did not affect the record as far as could be determined, nor did eye-opening.

A second record (Fig. 4), which was taken several days later, when the patient appeared alert and cooperative, 


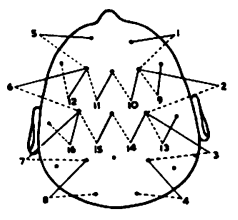

$100 \mathrm{uV}$ Usec.

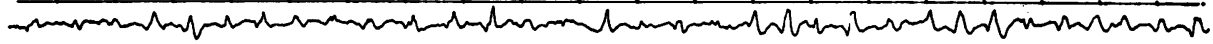

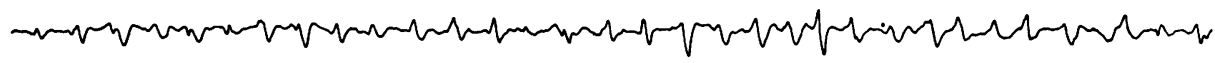

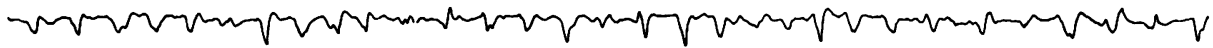

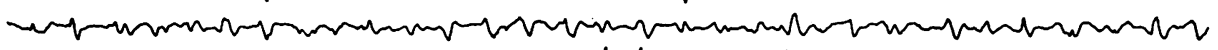

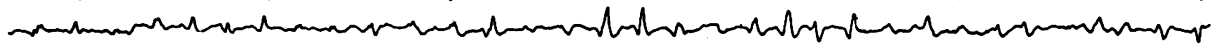

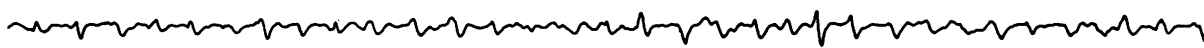

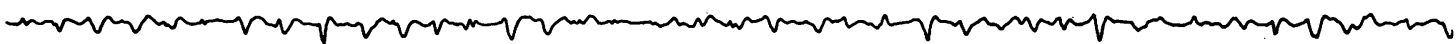

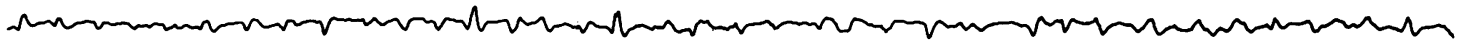

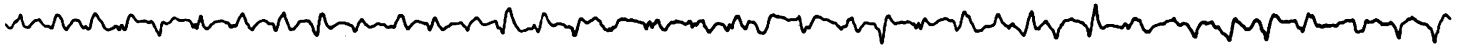

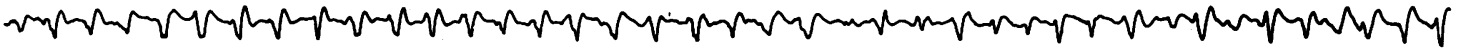

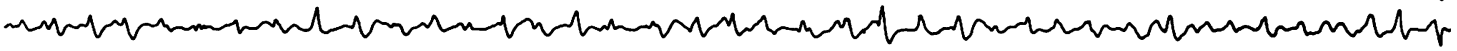

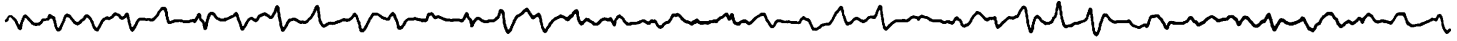

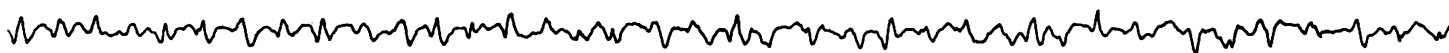

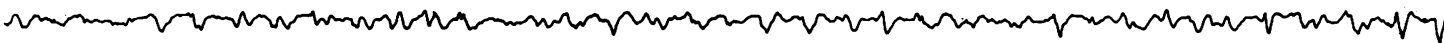

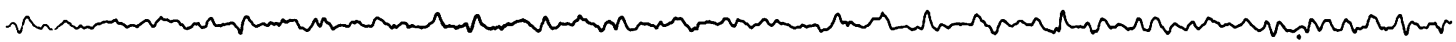

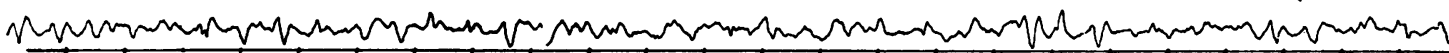

FIG. 3. First record from case 2 which show repetitive di-and triphasic sharp waves synchronous in all channels and repeating regularly at about one per second.

no longer showed repetitive sharp waves. With the eyes closed there was a generalized excess of slow activity consisting of mainly irregular, but occasionally rhythmical, theta and delta discharges. The rhythmical slow activity was most marked in the central regions, but at times was generalized, synchronous and symmetrical, and occurred in a rather paroxysmal fashion. With the eyes open the record was dominated by very low-voltage, irregular slow activity.

The E.E.G. showed a considerable improvement over the initial record, but was still thought to indicate a diffuse disorder of cerebral metabolism.

Further investigations Adequate temperature recordings on this patient were not obtained for some time after admission to the warm hospital environment, as her clinical state did not at once suggest the diagnosis of accidental hypothermia. Because it seemed important from the point of view of future management that a firm diagnosis be reached in this patient, the following investigations were performed. The patient lay in a room cooled to $50^{\circ} \mathrm{F}$. $\left(10^{\circ} \mathrm{C}\right.$.) with one covering blanket and the E.E.G. was recorded continuously as was the rectal temperature which was initially $100^{\circ} \mathrm{F} .\left(37 \cdot 8^{\circ} \mathrm{C}\right.$.). After two hours of exposure under these conditions, the rectal temperature fell to $96.0^{\circ} \mathrm{F}$. $\left(35 \cdot 6^{\circ} \mathrm{C}\right.$.) and it was thought unjustifiable to lower the temperature below this level in case her former serious clinical state was provoked. During this two-hour period the patient felt cold and drowsy and eventually slept but was easily rousable. She complained of a similar unpleasant subjective sensation to that experienced on admission to hospital. There was no overt shivering, but she briefly exhibited some slow involuntary movements of her feet resembling those seen on admission.

Initially (rectal temperature $99^{\circ} \mathrm{F}$. $\left(37 \cdot 2^{\circ} \mathrm{C}\right.$.) the E.E.G. (Fig. 5) was largely normal, though there were occasionat brief runs of 4 c.p.s. activity, sometimes associated wit sharp transients in both temporal regions. As her temperature fell, the record became more abnormal with intermittent generalized outbursts of delta activity and occasional sharp transients appeared (Figs. 6 and 7). The E.E.G. appearances, however, did not resemble entirely those seen in the initial record taken from this patient, nor did the patient develop the striking clinical manifestations evident at the time of her admission.

\section{DISCUSSION}

There is a very strong circumstantial evidence that the second patient was suffering from the effects of accidental hypothermia on her second admission to hospital. First, some of her subjective and objective changes could be reproduced by inducing even mild hypothermia, although only minor abnormalities could be reproduced in her E.E.G. Secondly, despite experimental lowering of her body temperature, shivering was not provoked which suggests that she had some derangement of the mechanism of regulation of body temperature. Her original clinical state in many ways was similar to that of the first patient and certain features, such as generalized rigidity (Duguid, Simpson, and Stowers, 1961; 음 금 


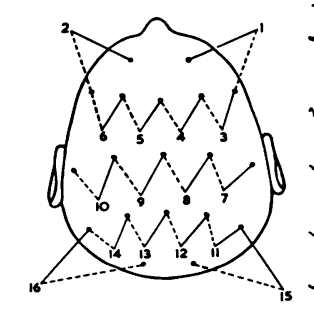

$100 \mu \mathrm{V}$ Usec.

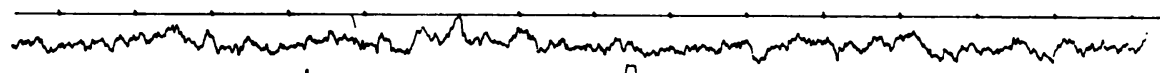

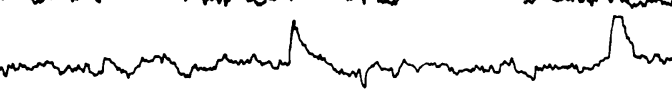

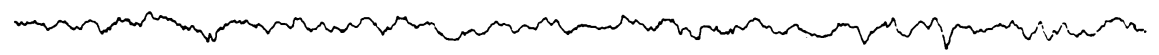

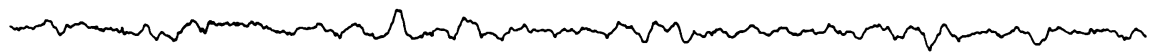
(1)

ror

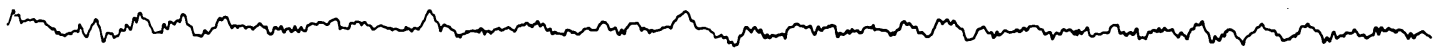

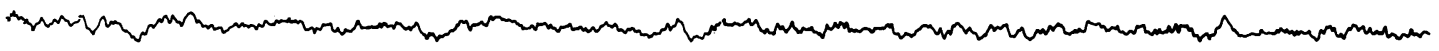

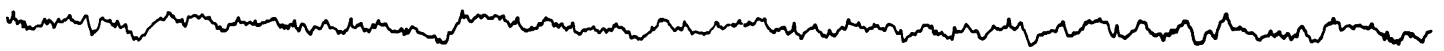

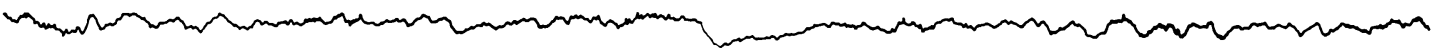

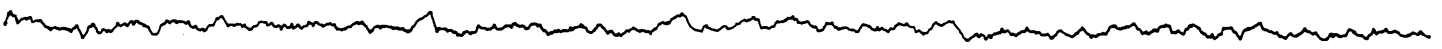

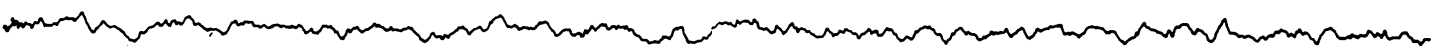

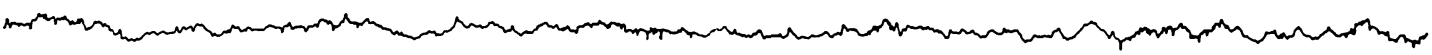

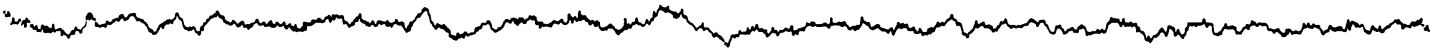

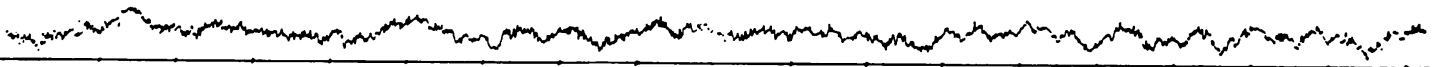

FIG. 4. Record from case 2, taken three days after the initial tracing, shows a generalized excess of slow activity but no paroxysms.

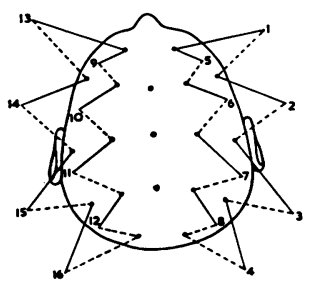

$100 \mu \mathrm{V}$ Usec.

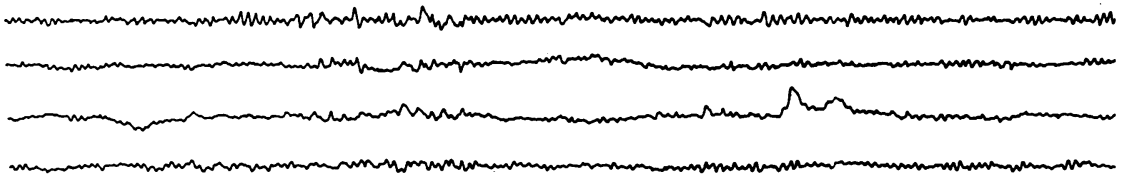

201 (1)

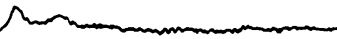

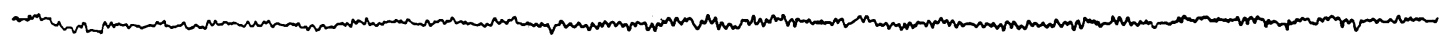

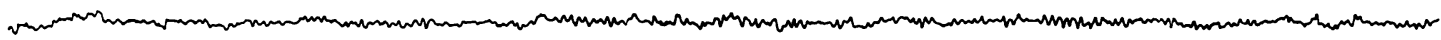
2 תחר

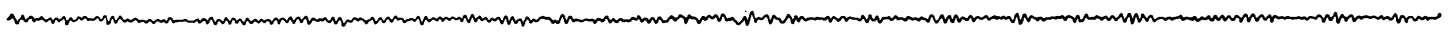

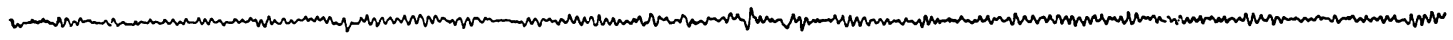
TEMP 99 (R)

FIG. 5. Case 2, before cooling. Rectal temperature $99^{\circ} \mathrm{F} .\left(37 \cdot 2^{\circ} \mathrm{C}.\right)$. Much of the record is normal. Occasional sloiv waves and sharp transients are seen in the temporal regions. 

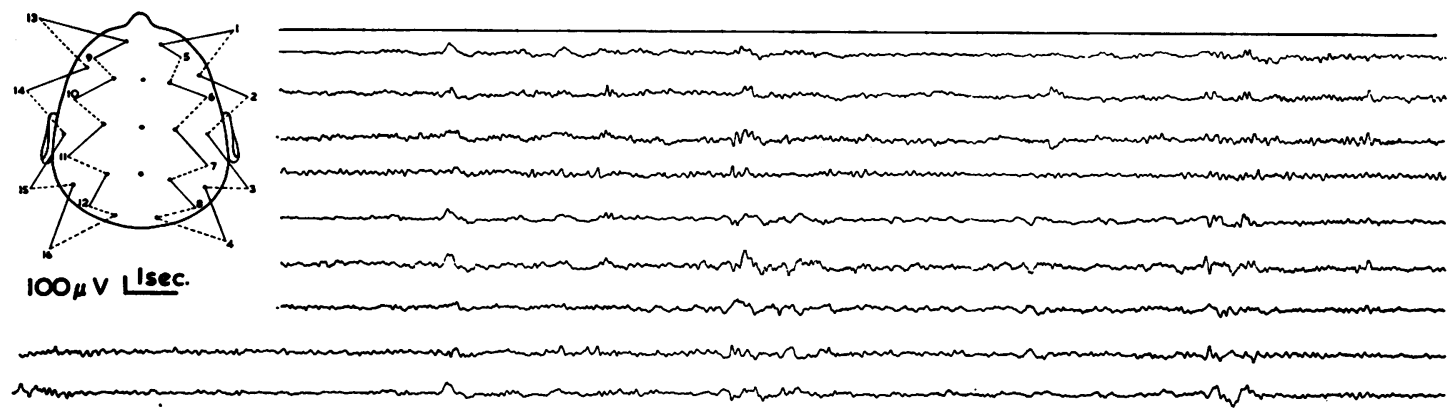

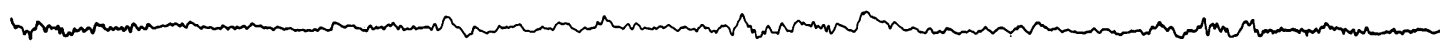
(1) (1) (1)

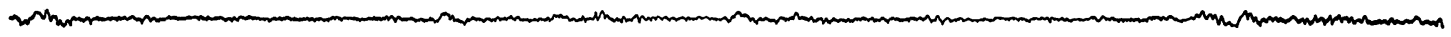
rem

FIG. 6. Case 2. Rectal temperature $97 \cdot 3^{\circ} \mathrm{F} .\left(36 \cdot 3^{\circ} \mathrm{C}\right.$.). Runs of slow waves and some sharp transients are seen.

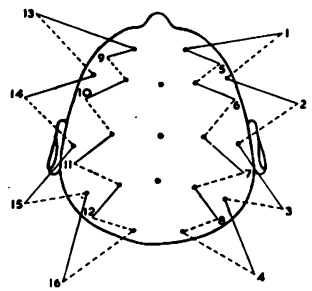

$100 \mu \mathrm{V}$ Lisec.

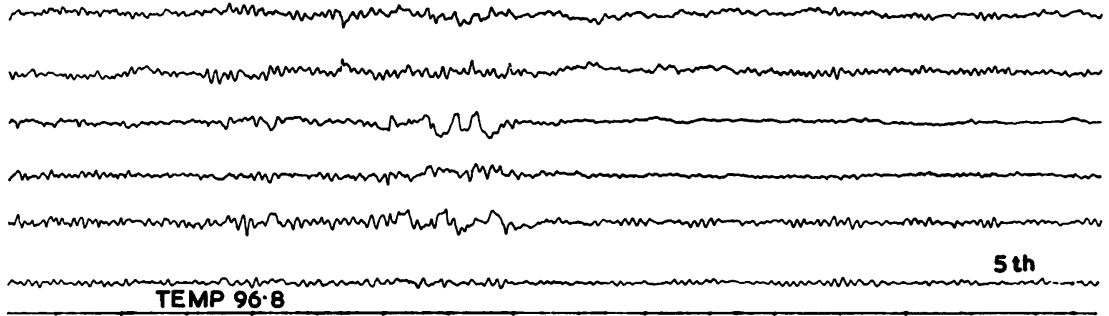
TEMP 96.8

FIG. 7. Case 2. Rectal temperature $96 \cdot 5^{\circ} \mathrm{F}$. $\left(35 \cdot 8^{\circ} \mathrm{C}\right.$.). A fairly generalized paroxysm of mixed slow activity and sharp transients is seen. At this stage some involuntary movement of the legs occurred. 
Rees, 1958), flapping tremor, and neck stiffness (Rosin and Exton-Smith, 1964) have been observed previously in hypothermic patients. Moreover, the E.E.G. findings in both our cases were remarkably similar. The E.E.G. in the first patient was recorded during the hypothermic phase and although $\mathbf{J}$ waves described by Osborn (1953) were not present, QTc was prolonged, as in Emslie-Smith's (1958) experience, and muscle tremor artefact was present as has been observed by Duguid et al. (1961).

The striking E.E.G. abnormalities in the initial records obtained from both patients are of interest. They do not resemble those seen in induced hypothermia as carried out in preparation for cardiac and brain surgery (Scott, 1955; Pampiglione and Waterston, 1958). The usual changes described in such cases take the form of gradual lowering of frequency and decrease in amplitude. However, these appearances may be in part due to anaesthetic or other drugs concurrently administered. In some previous reports of accidental hypothermia the E.E.G. has been markedly abnormal, and various authors (Bauer, 1954; Hockaday, Granston, Cooper, and Mottram, 1962) have demonstrated the presence of hypothalamic lesions at necropsy in patients with accidental hypothermia. Duff, Farrant, Leveaux, and Wray (1961) described E.E.G. studies in one of their cases which showed gross generalized abnormalities thought to be unassociated with epilepsy. The changes described appear to be quite different from those found in the two patients reported here. Hockaday et al. (1962) performed E.E.G.s on their three patients, and found grossly abnormal records with bilaterally synchronous high-voltage slow waves. Again these descriptions differ from our findings, and must be considered in the light of the more complicated cerebral pathology that was present in their cases.

We have already commented upon the similarity of the appearances present in the initial records obtained from our two cases to those seen in the Nevin-Jones type of encephalopathy. In fact this diagnosis was also considered in the second patient because the abnormal movements were thought to represent the myoclonic jerks described in that condition. It has been said that E.E.G. appearances of this type which occur in middle age are usually of gloomy prognostic significance, and are associated with a rapidly progressive dementia and a fatal outcome (Abbott, 1959; Lesse, Hoefer, and Austin, 1958; Pallis and Spillane, 1957). Similar changes have been reported to occur transiently in a case of cerebral fat embolism (Müller and Klingler, 1965).

The abnormal E.E.G.s in our two cases cannot simply be due to the presence of Parkinsonism. In this condition the E.E.G. changes (England,
Schwab, and Peterson, 1959) are usually relatively slight, and consist of posterior rhythms below 8 c.p.s. and a slight theta excess.

It seems possible that the combination of hypothermia and basal ganglion disease, in the two cases reported here, resulted in a similar though temporary neurophysiological derangement to that associated with the Nevin-Jones syndrome.

Histopathological changes may be found in the hypothalamic nuclei in patients with Parkinson's disease (Greenfield, 1963) so that it is to be anticipated that dysthermic episodes might occur in such patients. Autonomic disturbances and excessive tolerance to cold are well described clinical features in this disorder (Brain, 1962) and the latter feature, particularly, could be a predisposing factor to accidental hypothermia. It is true that other predisposing factors also existed in our two patients. In the first case, the patient was elderly and senile and had bronchopulmonary infection (Duguid et al., 1961); the second was receiving a drug pharmacologically related to imipramine and chlorpromazine (Prescott, Peard, and Wallace, 1962; McGrath, and Paley, 1960) and was living in an inadequately heated room.

\section{SUMMARY AND CONCLUSIONS}

Two patients with Parkinson's disease who developed accidental hypothermia are described. The E.E.G. findings in these two cases were remarkably similar and consisted of appearances not unlike those described in subacute spongioform encephalopathy.

These E.E.G. changes were reversible and were commensurate with general clinical improvement rather than with restoration of normal body temperature. It is suggested that Parkinson's disease may be a further predisposing cause of accidental hypothermia and this may in part be due to involvement of the hypothalamus in the disease process.

We should like to thank Dr. J. N. Walton for his encouragement and kind permission to publish the reports of these two patients, who were under his care at the Regional Neurological Centre, and Miss B. P. Longley for technical assistance.

\section{REFERENCES}

Abbott, J. (1959). The E.E.G. in Jakob-Creutzfeldt's disease. Electroenceph. clin. Neurophysiol., 11, 184-185.

Bauer, H. G. (1954). Endocrine and other clinical manifestations of hypothalamic disease. J. clin. Endocr., 14, 13-31.

Brain, W. R. (1962). Diseases of the Nervous System, 6th ed., p. 476. Oxford University Press, London.

Duff, R. S., Farrant, P. C., Leveaux, V. M., and Wray, S. M. (1961). Spontaneous periodic hypothermia. Quart. J. Med., 30, 329338.

Duguid, H., Simpson, R. G., and Stowers, J. M. (1961). Accidental hypothermia. Lancet, 2, $1213-1219$. 
Emslie-Smith, D. (1958). Accidental hypothermia-a common condition with a pathognomonic electrocardiogram. Ibid., 2, 492-495.

England, A. C., Schwab, R. S., and Peterson, E. (1959). The electroencephalogram in Parkinson's syndrome. Electroenceph. clin. Neurophysiol., 11, 723-731.

Greenfield, J. G. (1963). Neuropathology, 2nd ed., p. 583. Arnold, London.

Hockaday, T. D. R., Cranston, W. I., Cooper, K. E., and Mottram, R. F. (1962). Temperatu: regulation in chronic hypothermia. Lancet, 2, 428-432.

Jones, D. P., and Nevin, S. (1954). Rapidly progressive cerebral degeneration (subacute vascular encephalopathy) with mental disorder, focal disturbances and myoclonic epilepsy. J. Neurol. Psychiat., 17, 148-159.

Lesse, S., Hoefer, P. F. A., and Austin, J. H. (1958). The eletcroencephalogram in diffuse encephalopathies. Arch. Neurol. Psychiat. (Chic.), 79, 359-375.

McGrath, M. D., and Paley, R. G. (1960). Hypothermia induced in a myxoedematous patient by imipramine hydrochloride. Brit. med. J., 2, 1364.
Müller, H. R., and Klingler, M. (1965). The electroencephalogram in cerebral fat embolism. Electroenceph. clin. Neurophysiol., 18, $178-86$.

Osborn, J. J. (1953). Experimental hypothermia; respiratory and blood pH changes in relation to cardiac function. Amer. $J$. Physiol., 175, 389-398.

Pallis, C. A., and Spillane, J. D. (1957). A subacute progressive encephalopathy with mutism, hypokinesia, rigidity, and myoclonus. Quart. J. Med., 26, 349-373.

Pampiglione, G., and Waterston, D. J. (1958). Preliminary E.E.G. observations during partial and complete occlusion of cerebral blood flow. Electroenceph. clin. Neurophysiol., 10, 354.

Prescott, L. F., Peard, M. C., and Wallace, I. R. (1962). Accidental hypothermia: a common condition. Brit. med. J., 2, 1367-1370.

Rees, J. R. (1958). Accidental hypothermia. Lancet, 1, 556-559.

Rosin, A. J., and Exton-Smith, A. N. (1964). Clinical features of accidental hypothermia, with some observations on thyroid function. Brit. med. J., 1, 16-19.

Scott, J. W. (1955). The E.E.G. during hypothermia. Electroenceph. clin. Neurophysiol., 7, 466. 